\title{
Classification and Symbols of Masses in the Conception of Elias Canettii
}

\author{
Nikolay Angelov Tsenkov \\ South-West University "Neofit Rilski”, BULGARIA \\ Faculty of Philosophy, Blagoevgrad
}

Received: 3 March 2019 • Accepted: 12 June 2019 • Published Online: 14 November 2021

\begin{abstract}
The article focuses on the types of masses and their symbols according to Elias Canetti, which he presents in his large-scale work Masses and Power. The main forms of the masses are classified, according to their functional characteristics. Various natural phenomena and clusters are natural combinations of symbolic significance, carried away from ancient times to the present day through myths, traditions, dreams, speech. Analogies are examined between the natural symbols of masses, which are absorbed and carried by man as attributes of the masses in the social reality.

Keywords: Elias Canetti, masses, classification, symbols.
\end{abstract}

\section{Introduction}

Although the first edition of Elias Canetti's book Crowds and Power was released as late as 1960, the author himself states that as early as 1924, barely twenty years old, he was overwhelmed, even obsessed by the idea to write a book on masses. An important event that enticed him to embrace this endeavour was the torching of the Court of Justice in Austria's capital on 15 July 1927. "The police had been ordered to shoot at the rebellious workers - more than 90 people were murdered!" Elias Canetti was one of those rioters: "I became part of the crowd, I merged with it. I did not try to oppose its actions" (Canetti, 1980: 245).

The author of Crowds and Power considers masses as an anthropological source of history driven by the endless cycle of self-preservation and extermination of mankind. According to Arnason and Roberts (2004), in Canetti's interpretation, culture is reduced in the last instance to nature, inhabited and actuated by the masses. Canetti argues that the fear of being touched by the unknown and the unexpected is at the heart of the psychological reflex to "merge" in a crowd. It is only in a crowd that man feels secure and equal to others, the only situation in which the fear changes into its opposite. The more fear is generated, the more quickly and spontaneously a mass appears. However, this "security and power", or rather the feeling of "un-touchability" in the crowd, appear at individual psychological level. They are typical but come at a high price! At social level crowds are the conditio sine qua non of dictatorial regimes: the "individual in the crowd" has lost his individuality and identity, he has no face; his de-individualization invites for manipulation and subjugation to any kind of ideology (Lozev, 1990: 65-67).

(C) Authors. Terms and conditions of Creative Commons Attribution 4.0 International (CC BY 4.0) apply. Correspondence: Nikolay Angelov Tsenkov, South-West University "Neofit Rilski", Faculty of

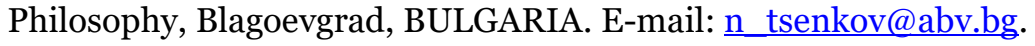


The future Nobel Prize winner Canetti defined four major attributes of the crowd. The first one is growth, to which there are no natural boundaries. Where such boundaries are artificially imposed, an eruption of the mass is always possible and will transform the type of the crowd from closed to open. The second attribute is equality. According to Canetti, the most important occurrence within a crowd is the discharge. Before this the mass does not actually exist. Discharge is the moment when all who belong to the crowd get rid of their differences and feel equal. Then an immense feeling of relief ensues and men free themselves from their inhibited fear of being touched, which underlies the formation of the crowd. The third attribute is density. Canetti holds that a crowd can never feel too dense. Nothing must stand between its parts or divide them. Everything must be the crowd itself. The last attribute is the need for direction. "A crowd exists," writes Canetti, "so long as it has an unattained goal" (Canetti, 2018: 26). The crowd is in perpetual movement in a direction, which is essential for its existence. Moreover, the direction, the common goal strengthens the feeling of equality in the crowd. All members of the mass are united for achievement of the common goal, which drives underground all their private different goals (Canetti, 2018: 26).

\section{Classification of masses}

The author of Crowds and Power devotes a considerable part of his survey to the classification of crowds in terms of their predominant attribute. He classifies them into open and closed masses. Masses are open when their growth is not impeded. An open mass pretends to be omnipresent, it wants to seize everyone within reach, it does not know borders and barriers: "...it does not recognize houses, doors or locks and those who shut themselves in are suspect". "Open" is to be understood here in the fullest sense of the word; it means open everywhere and in any direction. The open crowd exists so long as it grows; it disintegrates as soon as it stops "growing" (Canetti, 2018: 11) Contemporary manifestations of the open mass are the demographic boom and the rapid expansion of the big cities. In contrast to the open crowd, there is the closed mass, which renounces growth and has a boundary which provides the crowd with stability. In a historical context, the closed masses from the past are a prototype of the common institutions. Their essential feature is limitation. They establish a boundary which prevents disorderly increase. The closed mass loses its chance to grow but gains in sustainability. Examples of such masses are certain professional guilds, religious communities, political formations, sports fan clubs, syndicates, etc. The closed crowd renounces the unlimited growth - it does not need integration but rather a segregation from the other crowds in order to justify its existence. If we compare a closed mass to a wall (which by definition could not be unlimited), then the mortar which binds its bricks is the repetition. It is the expectation of repetition which prevents the mass from disintegration. The above examples can be illustrated with some repetitive manual labour operations, the repetition of prayers, the cyclic political elections, the expectation of football fans to watch the next game of their favourite team, etc. Naturally, quite often, a closed mass is so obsessed to pursue its goal that it becomes forgetful of its boundary and becomes an open mass. Such transformational processes are usually the revolutions (from guerrilla groups to people's power), the coups (from a political elite to a national movement), the wars (from a revanchist groups to mass militarist coalitions), etc.

Canetti further classifies masses in terms of their functional characteristics. The first category is the rhythmical mass. When human beings became Homo Erectus, they started using their feet in a completely different way. "Rhythm is originally the rhythm of the feet", explains Canetti (2018: 28) Then men discovered the oldest language - they learnt how to interpret animal tracks in order to understand the rhythm of large groups of animals, which were domesticated later on. The typical tribal dances around the camp fire are a good example of a rhythmic crowd. All crowds are similar in terms of their rhythm. There are also stagnant masses, which are closely compressed, passive, and patient. Such are the spectators of sport events, theatrical performances, 
and concerts. The duration of these events and their structure are set in advance and the crowd is allowed to express its emotions in certain ways - through applause or cheers. Canetti gives an extremely impressive example for a stagnant crowd with the famous Standing on Arafat, the climax of the pilgrimage to Mecca. Only a few hours away from their final destination, a few hundred thousand pilgrims gather on the plain of Arafat on a ritually appointed day. Bareheaded, they group themselves in a large circle round The Mount of Mercy towards two o'clock, when the sun is hottest, and remain there until it sets.

The slow mass has the form of a procession. It has set off on a long journey and no discharge is allowed before the goal has been reached. The exodus of the Jews and their journey towards the Promised Land illustrates this slowness - the old die and new babies are born. This is exactly what must happen until the people of Israel reach their goal - a whole generation must be replaced. Invisible masses are usually composed of the invisible dead. The conception of the invisible dead is probably humanity's oldest conception. Without further ado, here we will only quote the Canetti's example regarding the Celts of the Scottish Highlands: "The word gairm means shout or scream, and sluagh-ghairm was the battle-shout of the dead. This word later became "slogan". The expression we use for the battle shouts of our modern masses derives from the Highland hosts of the dead" (Canetti, 2018: 42).

In terms of their prevailing affection, Canetti distinguishes the baiting mass, which forms with reference to a quickly attainable goal usually associated with violence and most often than not with the physical murder of a designated victim. There are many historical examples of baiting crowds, where the victim is stoned, burned on the stake, shot dead by a firing squad, beheaded with a guillotine or sword or buried alive in an anthill, which was a customary execution method of some African tribes. Everyone participates in the killing and no-one has been appointed executioner. The members of a baiting crowd are guided by two basic psychological impulses. The first one is the discharge "from the fact that the victim, who has oppressed or threatened them, is no longer a threat for them; They become equal to it by the act of its destruction" (Gradev, 2005: 407). The second impulse is the illusionary suppression of the common fear of death by "transferring" death on the victim by collectively killing it.

Canetti continues with the flight mass. Such a crowd is created by a threat and has a single purpose - survival. In collective flight the energy of some increases the energy of others and the distances between its members disappear. What is more, the crowd has the illusion that the danger is distributed equally so long as they keep together. The personal threat is reduced to a common threat, the individual fear is transformed into a shared fear; my salvation requires a collective effort - the flight. Good examples of flight crowds are the refugee waves in various historical periods. The flight masses are disintegrated in three different scenarios. The first two are natural and logical - when the goal of salvation is attained or when the threat has ceased to exist. However, there is yet a third option, which Canetti calls "the oozing away of the flight in sand". The crowd disintegrates because the goal is too far off, the threat is too great and the people grow exhausted. "A large number of people together refuse to continue to do what, till then, they had done singly" - Canetti wrote in the introduction to prohibition masses (Canetti, 2018: 55). Once a prohibition is imposed, a resistant mass begins to form. It is negative in character since it is based on refusal. Prohibition crowds are formed by resistance; they refuse to obey the accepted public regulation standards. A good example for a prohibition crowd is the strike - the collective refusal of workers to continue doing their individual jobs. The refusal to obey is what makes the members of the mass feel really equal.

Reversal crowds were formed in many turning points in history. Reversals aim to destroy or rearrange a stratified society. They are revolutionary in essence because in addition to overthrowing the existing norms, they institute new ones. According to Gradev, reversal crowds are formed "in the process of collective deliverance from the many painful "stings" of command" (Gradev, 2005: 413). These "painful stings" are left by the commands the person was forced to 
carry out. Canetti gives an example with the storm of the Bastille during the French Revolution, when the crowd set free the prisoners, who were able to join the crowd, but thieves, too, were strung from the lamp posts. By storming the Bastille, the crowd took over justice in two main aspects - the right of inflicting capital punishment and the right of mercy. Unlike the flight crowds, which are formed when a threat arises, a feast crowd is formed by abundance. During the feast many prohibitions and distinctions are waived and unaccustomed advances are not only permitted but smiled on - everyone is allowed to participate in the festive rituals. Dances (e.g. the circle dance at a wedding) and festive rituals (e.g. the making of ritual breads) involve and engage all participants. Violence, which is characteristic of most crowds, is not associated with this type of crowd. On the contrary - during the feast "there are no enemies, there is no common identical goal or threat which people have to attain or flee from" (Gradev, 2005: 413). Feasts imply repetitiveness and temporal continuity; feasts call to one another and everyone is assure in their future repetitions.

\section{Symbols of masses}

Mass symbols is the name given by Canetti to collective units which do not consist of men, but which are still felt to be masses. They are various natural and geographical phenomena allude to some of the essential attributes of the crowd and stand as symbols for it in myth, tradition, dream and speech. Canetti finds analogies between these natural collective units that symbolize human masses in society. Fire is such a symbol. The author of Crowds and Power describes its attributes in relation to mass characteristics: "Fire is the same wherever it breaks out: it spreads rapidly; it is contagious and insatiable; it can break out anywhere, and with great suddenness; it is multiple; it is destructive; it has an enemy; it dies; it acts as though it were alive, and is so treated" (Canetti, 2018: 79). All this is true of the mass - it can be formed anywhere and expands rapidly like fire, it wants to grow and is contagious. It is amorphous like glowing ambers and yet united, it comprises an indefinite number of people. Like fire, it can be destructive and seeks an enemy to destroy (baiting crowd, reversal crowd). The crowd discharges as suddenly and quickly as fire dies; it has its own turbulent and intensive life. The likeness between fire and the mass has led to the close assimilation of their images. Since ancient times, man has been trying to tame the fire, to merge with it, and even to become fire. The absorbing flames and their vital warmth seem to hypnotize the individual who, though he has learned to tame fire, remains obedient to its overwhelming power.

Another crowd symbol is the sea. It is all-embracing and can never be filled and thus serves for a model for the mass, which always wants to grow and would like to become as large as the sea. The sea consists of a vast multitude of individual drops of water, which are united to become part of a whole. Similarly, separated human beings ("a drop in the sea") unite into a crowd ("a sea of people"). Sea waves are innumerable and their motion is determined by the wind. Like men in a crowd who strive to attain a certain goal, the waves follow the direction towards the infinity. They are ceaseless. Like a crowd, they can become huge and then disappear instantly. The sea is vital, it never sleeps. The mass wants to resemble the sea in order to overcome its greatest fear - its discharge. The sea gives life to millions of organisms in and above it. It unites the inflows of streams and rivers, collects the water of the rain from the clouds above and the glaciers along its shores, but these dynamic processes do not disturb its natural rhythm of life in which everything is united, distributed and circulated. "With the living is the sea in love / the dead are cast ashore", wrote Hristo Fotev - a poet from Burgas, who dedicated most of his works to the watery expanse of the sea (Fotev, 1998: 25). The destructive power of the sea is another attribute which resembles a crowd. Those who disregard the laws of the sea can be engulfed by it. The density of the sea and its coherence "is something which men in a crowd know well: it entails a yielding to others as though they were oneself ..." (Canetti, 2018: 83). Naturally, the attributes of 
the sea are too comprehensive to correspond exactly to any of the crowds we know - they can only strive to attain them.

Rain is another symbol. Like the sea, rain consists of innumerable drops. However, all languages speak of rain, rather than drops, falling. Similarly, we speak of the crowd rather than the separate humans in it. We are all familiar with the calmness just before a storm. The sky turns grey; heavy clouds block the sun. The dark, destructive impulses of a crowd are very similar to the destructive power of the downpour, which can flood houses and gardens, demolish streets and bridges, destroy the crops (hail is the hard aggregate form of rain.) No human action can stop the rain from falling. Like crowds, which always pursue a certain goal, rain always falls from above from the sky to the ground. "There is a sameness in the impact of rain-drops, and the parallel lines of their fall and the uniformity, both of their sound and of their wetness on the skin, all serve to accentuate this sameness" - explains Canetti (2018: 86). Unlike the raging of fire and the constant presence of the sea, rain is the mass in the moment of discharge. The clouds dissolve into rain and the sun shines again.

Another mass symbol discussed by Canetti is the river. We say that one "goes with the flow" when they lack initiative and ambition. The most striking thing about a river is its direction - it can only flow in one direction - to the sea - and without a direction it would not be a river. This is why the river stands for processions, demonstrations and tributaries, which always flow in a certain direction like the river flows toward the sea (another crowd symbol). In his book "The Fratricides" Nikos Kazantzakis (Kazandzakis, 2018: 18) skillfully depicts the inflow of a river into the sea and its symbolic significance through a dialogue between a young priest and an old man beholding the stream:

"What are you looking at, grandfather?" he asked with curiosity.

The old man raised his head and smiled sadly. "At my life flowing and

disappearing, son, flowing and disappearing."

"Don't worry, grandfather, it knows where it is going-toward the sea, everyone's life flows toward the sea."

The old man sighed. "Yes, my son, that is why the sea is salty - from the many tears."

A river is the crowd in its "vanity". All river-like formations want to be seen. A crowd in motion along the streets of a large city (a procession, a demonstration, a tributary, etc.) resembles the flow of a river between its banks. Along its route to the sea, the river can become destructive just like a crowd. It can overflow its banks and flood towns and villages. The equality of the water drops in a river is apparent. However, a river does not have the raging of the fire, the universality of the sea or the discharge of the rain. The river is a symbol of the movement of a crowd, which is still under control and has not achieved its goal yet.

Forest is an extremely expressive mass symbol. It may be overgrown with shrubs, but its real density, which makes it's a forest, is its foliage. It is the overhead foliage of single trees, which, linked together like the water drops, forms a continuous roof which shuts out the light and defines the skyline. The linked crowns of its trees create a sense of protection "from above". In the mass, man feels equal to the others and sheltered by the forest. He stands upright like a tree and inserts himself amongst the other trees, from which he has descended, if we believe the evolution theories. As Canetti wrote: "The direction in which a forest draws men's eyes is that of its own growth. A forest grows steadily upward" (Canetti, 2018: 86). The forest compels men to look upwards, grateful for the protection above. Thus the forest is the first image of awe, the religious feeling of standing before God. Another aspect of the forest is that it is immovable and solid. Every tree is deeply rooted in the ground. It can be cut down but cannot be moved. This makes the forest authentic symbol of the army - a solid mass which has taken up position and will neither surrender nor flee and which allows itself to be cut down to the last man before it gives a foot of 
ground. Compared to the other crowd symbols, the forest has "the persistence of the river, the density of the rain and the mysteriousness of the fire" (Gradev, 2005: 442).

The next symbol discussed by Canetti is wheat, which is defined as a diminished and subjugated forest. It grows where forest stood before. Wheat is sown and reaped, and thus multiplied. It multiplies like a crowd. Wheat stalks are perfectly equal in height. The innumerable small seeds are sown, germinate and grow together and are reaped together. Their rhythm when excited by the wind is that of a simple dance. This symbolizes the submissiveness of the mass. Even when they are struck down by a storm, when they straighten up, they are equal once again. A cornfield as a whole generally appears uniform in height. According to Canetti, "The full ears are like heavy heads; they nod to one or turn away as the wind blows" (Canetti, 2018: 89). All blades of wheat grow in the same direction - from the ground to the sky. Anything which happens to one happens to all. The germination of the seed and the harvest of the wheat are the beginning and the end of a natural cycle similar to the cycle of life and death of the humans. Harvest follows the sowing like death follows. Again and again - to eternity. The Eucharist, the main sacramental ceremony of the Church, commemorates the Last Supper, when Jesus Christ gave to his disciples bread as a symbol of His body - While they were eating, Jesus took bread, and when he had given thanks, he broke it and gave it to his disciples, saying, "Take and eat; this is my body" (Mathew 26: 26-28). And yet, on All Souls' Day we honour the souls of the dead and give to our relatives boiled wheat as a symbol of resurrection in a ritual symbolizing the endless cycle of life and death (“...unless a kernel of wheat falls to the ground and dies, it remains only a single seed. But if it dies, it produces many seeds" (John 12: 24)).

The next symbol is wind. We often wonder where the wind comes from when we want to understand what is going to happen. The most striking thing about wind is its direction. The strength of the wind varies and it has many faces. What is interesting is that although they cannot see it, people have various names for it - for example, on the Southern Black Sea coast the locals use the names "sereco" for the southeastern, pleasant sea breeze, "levanti" for the dangerous eastern wind, "meltem" for the dead wave wind, and so on. Wind is invisible, but its movement is apparent - it moves the clouds, drives the waves, bends the branches of the trees. It can whine or howl, it can bring coolness or destroy, it is as ambivalent as a crowd. Since ancient times wind has been associated with breath in terms of its density. But on the other hand, its invisibility enables it to stand for invisible crowds, and thus for spirits.

Sand as a mass symbol has two especially important qualities - the first is the smallness and sameness of its grains and the second is its endlessness. The sameness of the sand is associated with the sameness of men in a crowd and the reduction of their psychological differences. Its endlessness is associated with the crowd's aspiration for perpetual growth. Insignificant on their own, sand grains are united in an endless multitude - the monotonous, vast and lifeless desert. Heaps of fruit or grain symbolize the result of activity of many hands occupied with the picking or harvesting. The size of the heap is as important as the size of the crowd - their goal is to grow. Men celebrate in feasts the heaps they have managed to collect. Apart from these festive heaps, Canetti writes about stone heaps, which are also the result of collective human efforts. As a manifest mass behavior, this symbol clearly stands out in some protests in which the disgruntled "heaped children's shoes or other objects in squares and in front of government offices, so that society can literally see the hardships of the economically deprived people" (Gradev, 2005: 446). The last symbol described by Canetti in his classification of crowd symbols is treasure. Its main function is to be safeguarded and amassed. A hoard of treasure can be won openly through competition on all kinds of lottery, as well as to be depreciated through inflation caused by a mass in flight. 


\section{The order}

A key element of Canetti's concept regarding mass is their relation to power, an important manifestation of which is the order. In reality, individuals are driven to social activity through regulations, i.e. have to obey orders. This applies to all social spheres - politics, religion, family relations, economics, etc. - which impose individual codes of conduct. All statutory regulations, religious dogmas, educational principles, business rules, etc. are, in their essence, collective orders. An order is considered as natural as it is necessary. In a famous radio conversation with Theodor Adorno in 1962, the author of Crowds and Power described how the impulse to reject these collective orders is a sub-conscious mass-formation factor:

“...no-one who has carried out an order has in no way enjoyed this. He may not be aware of it; he may not think about it. But the sting of the order remains stuck in the individual. And this is especially important. In this way, people can accumulate many stings from orders received twenty or thirty years ago. People want to free themselves from these stings, and that is why they often seek out situations that are the exact reverse of the original situation in which they received commands, in order to get rid of the sting. The consequences of this desire are clear. Everyone who lives in a society is pierced by many such stings. Their number can increase so much as to make him do monstrous acts because he suffocates from these stings." (Canetti, 1994: 463)

The many stings accumulated from repetitive and overlapping orders are very difficult to get rid of individually. According to Canetti, such deliverance is possible in a reversal crowd. It is a crowd whose discharge consists mainly in its collective deliverance from the stings of command (Canetti, 2018: 341). Throughout history there are numerous examples of such removal of stings: a king, who has repeatedly ordered the beheading of a lot of people is decapitated by the crowd, which has suffered these stings for a long time. The initial command situation is repeated, but in a reversed order. Then everything is repeated - those who acquired the power are afraid and are looking for a way to get rid of their fears by issuing the same kind of orders. This mechanism creates a vicious circle of issuing orders, followed by execution, then accumulation of stings, and again discharge at the end. (Against this 'vicious circle' Plato, one of the greatest philosophers, and perhaps the greatest inventor of ideologies (Popper), found a 'political cure': in his famous theory of 'the ideal city-state (Kalipolis)' he emphasizes the need for implanting universally the feeling of living in a 'just state' which means implanting the feeling of living in 'the perfectly organized and governed state' (Lozev, 2000, ch. 3)).

\section{Conclusion}

Elias Canetti belongs to those researchers who consider the mass man as an anthropological construct derived from the very human nature. This concept seeks the cause of crowds as a public phenomenon in psychological factors associated with intrinsic instincts, mass conduct codes, and unconscious psychic processes. According to Canetti, each human harbours the animal of the "mass" man. This is why Canetti's classification of crowds is historically universal, it is based on universal instincts (destructiveness), beliefs (ghosts of myths), rituals (pilgrimages), patterns of behaviour (flight from danger), and so on, which, under specific circumstances, become social processes. Mass symbols are not associated with cultural phenomena or historical periods - they are derived from nature (fire, wind, rain, etc.) and represent the natural attributes associated with the different types of mass. Crowd participation is not a social phenomenon pertaining to a certain historical period and manifest under specific circumstances. On the contrary, every person has the potential and need to become periodically "invisible", to feel relieved of the responsibility to be himself, to immerse his self in the anonymity of a crowd. 
N. A. Tsenkov - Classification and Symbols of Masses in the Conception of Elias Canetti

\section{Acknowledgements}

This research did not receive any specific grant from funding agencies in the public commercial, or not-for-profit sectors.

The author declares no competing interests.

\section{References}

Arnason, J., \& Roberts, D. (2004). Religion, Crowds, and Power. In: Elias Canetti's Counter-Image of Society: Crowds, Power, Transformation (pp. 59-78). Boydell \& Brewer.

Canetti, E. (1994). The Conscience of Words. Sofia: Hristo Botev.

Canetti, E. (1980). The Torch in My Ear. New York: Farrar, Straus \& Giroux.

Canetti, E. (2018). Crowds and Power. Sofia: Lege artis.

Fotev, Hr. (1998). Collective works. Sofia: Kazanski Publishing House.

Gradev, D. (2005). Psychology of masses. Sofia: Nauka i izkustvo.

Kazandzakis, N. (2018). The Fratricides. Sofia: Ciela.

Lozev, K. (1990).Totalitarianism as De-individualization. Philosophical Thought, 11, 62-70.

Lozev, K. (2000). The Social Philosophy of Karl Popper. Sofia: KALUS and Didakta Consult.

i The paper is previously published in T. V. Petkova \& V. S. Chukov (Eds.) (2019), 3th International $e$ Conference on Studies in Humanities and Social Sciences: Conference Proceedings (pp. 311- 318). Belgrade: Center for Open Access in Science. https://doi.org/10.32591/coas.e-conf.03.29311t 